\title{
Epidemiology of Depression in a Primary Care Setting in North Central Nigeria
}

\author{
Sanni $\mathrm{OF}^{1}$, Onuoha $\mathrm{Fm}^{2 *}$, Alabi $\mathrm{An}^{1}$, Ayinmode $\mathrm{BA}^{1}$ and Buhari $\mathrm{OA}^{3}$ \\ ${ }^{1}$ Department of Family Medicine, University of Ilorin Teaching Hospital, Nigeria \\ ${ }^{2}$ Department of Family Medicine, Federal Medical Center, Nigeria \\ ${ }^{3}$ Department of Behavioural Sciences, University of Ilorin Teaching Hospital, Nigeria \\ *Corresponding author: Onuoha Franklin M, Department of Family Medicine, Federal Medical Center, Owerri, Nigeria
}

Submission: 䟱 July 02, 2018; Published: 制 July 18, 2018

\begin{abstract}
There has been an increasing interest in mental health at the primary care level. This is because globally, mental illnesses are major contributors to the burden of diseases. It is on this premise that this study aimed at determining the prevalence and epidemiology of depression among adult patients assessing care in a primary care setting in the north central region of Nigeria was conceptualized. The study was a descriptive hospital based cross-sectional study in which data was collected from 425 adult patients attending the family medicine clinics of university of Ilorin Teaching Hospital (UITH), Ilorin, Nigeria between June and August 2016. Interviewer administered questionnaires were used for data collection. The Hospital Anxiety and Depression Scale (HADS) were used to screen the respondents for depression. Data were analyzed using the Statistical Package for Social Sciences version 21(SPSS-21). The prevalence of depression found in this study was $24.9 \%$. Age was the only Socio-demographic factor that was found to have a statistically significant association with depression ( $\mathrm{p}=0.045)$. In conclusion, depression was found to be common in the Family Medicine Clinics UITH. Primary care providers should have a high index of suspicion in the diagnosis and management of depression.
\end{abstract}

Keywords: Depression; Primary; Care; Nigeria

\section{Introduction}

Depression is a broad and heterogeneous diagnosis with the core symptoms of low mood and/or loss of interest in most pleasurable activities [1]. It is described by the world health organization as a common mental disorder that presents with depressed mood, loss of interest or pleasure, decreased energy, feelings of guilt or low self-worth, disturbed sleep or appetite, and poor concentration [2]. Both the International Classification of Diseases, $10^{\text {th }}$ edition (ICD10) and the Diagnostic and Statistical Manual of mental disorders, $5^{\text {th }}$ edition (DSM-5) have specific, though similar criteria for the diagnosis and classification of depression based on symptomatology and severity of symptoms [3-5]. Depression is a major contributor to the global burden of disease; affecting people in all communities across the world. It is estimated to affect about 350 million people worldwide [2]. It is the leading cause of disability among all adults' males and females worldwide [6]. Depressive disorders were the second leading cause of YLD (Years of life lived with disability) in 2010 and they are projected to reach second place in the ranking of disability adjusted life years (DALYs) calculated for all ages by the year 2020 [7,8]. The prevalence of depression varies from region to region across the world and varies between high income, middle and low income countries [7]. The prevalence of depression alone (without other co morbidities) among the general population was found to be $3.2 \%$ in a survey involving 60 countries of the world [9]. According to a meta-analysis carried out by Ferrari et al. [7], across most countries of the world, the average prevalence of depressive disorders in the Nigerian population was found to be $5.21 \%$ (3.69\% for Major Depressive Disorder and 1.52\% for Dysthymia).

The prevalence rates in primary care settings across the world however, showed far higher values ranging from $26.3 \%$ in Southern Asia and Kenya to $56.7 \%$ in a primary care centre in Paris, France [8,10-12]. In primary care settings in Nigeria, different prevalence rates have been reported. For instance, A prevalence of $24.5 \%$ was reported among outpatients attending the family medicine clinics at University of Uyo Teaching Hospital, South South, Nigeria, while in Sagamu Local Government Area, Ogun State, South West Nigeria, Ogunsemi et al. [13] found the prevalence of $29.1 \%$ for depressive disorders [12,13]. A prevalence of $59.6 \%$ was found by Afolabi et al. [14] among patients attending the family practice clinic in wesley guild hospital, Ilesa, also in South West Nigeria [14]. In a study done at Enugu, South East Nigeria, a prevalence of $14.9 \%$ was reported for depression among health workers [15]. Another study done in Kano, North West Nigeria, found a prevalence rate of $49.8 \%$ among attendees of the general outpatient clinic of a tertiary health institution [16]. Shittu et al. [17] in a similar study done in 
another primary care setting in Ilorin found a prevalence of $44.5 \%$ among adult patients attending the general outpatient clinics of Sobi Specialist hospital.

Different studies have reported an association between various socio-demographic factors and depression across the world. In Mexico, Bautista et al. [18] noted that female gender, lower level of education, lower income, and being separated or widowed were positively associated with depressive symptoms. These findings were like those recorded by Akhtar-Danesh et al [19] in Ontario, Canada and Afolabi and colleagues in Ilesa, South Western Nigeria [14,19]. Milanović et al. [20] in Croatia found no association between depression and gender. They however, found an association between depression and age, level of education, employment status and marital status. In Kano, North West Nigeria, depression was found to be more likely to occur in outpatients who were over 40 years, females, married respondents and those who had low level of education [16].

Conversely, Ogunsemi et al. [13] observed that gender and marital status were not associated with depression in their study in Sagamu, South West Nigeria. Shittu et al. [17] in Ilorin also found that depression was more likely to occur among the married group. Another study in Lagos, South West Nigeria, by Coker et al. [21] reported that only lack of formal education was predictive of depression among the socio-demographic factors studied. This finding is similar to the observation by Aillon JL et al. [10] and colleagues in Kenya where no association between sociodemographic factors and depression was reported. The above high-lighted disparities could be attributed to the differences in the study population, research methodology, time and duration of the different studies. Disparities in socio-economic factors as well as socio-cultural dynamism could have also contributed. The present study is therefore aimed at determining the prevalence of depression and its relationship with the socio-demographic characteristics of the target population.

\section{Materials and Methods}

\section{Study area}

The study was conducted at the general out-patient clinic (GOPC) of UITH, Ilorin. Ilorin is the capital city of Kwara State, located in the North-Central geopolitical zone of Nigeria. Kwara State shares boundaries with five other states in Nigeria, namely: Kogi, Ekiti, Osun, Oyo and Niger. Although majority of the inhabitants of Ilorin are Yoruba speaking, other tribes like Baruba, Nupe, Hausa, Fulani and Igbo also constitute a significant proportion of the population. The inhabitants are mainly civil servants, traders, farmers, artisans and private employees. The two major religions are Christianity and Islam. University of Ilorin Teaching Hospital is located in OkeOse, Ilorin-East local government area. It is a 500-bedded tertiary health institution. The department of family medicine represents the primary care unit of the hospital and accommodates the general out-patient clinic (GOPC) where the index study was conducted. The GOPC serves as a gate-way to the hospital through which all patients with the exception of emergency cases are admitted into the facility for care.

\section{Study design and population}

This study was a hospital based descriptive cross-sectional study carried out between June and August 2016. About 425 consenting adults aged 18 years and above who satisfied the inclusion criteria were recruited into the study. A systematic random sampling method was used in the selection of the respondents. Ethical approval was obtained from the ethical review committee of University of Ilorin Teaching Hospital, Ilorin, Nigeria. Respondents were adequately informed about the study and written informed consents were obtained from those who participated in the study. The respondents were made to understand that participation was entirely voluntary and that they were at liberty to withdraw from the study at any time they wished. They were also informed that their refusal to participate in the study would not attract any penalty. Information obtained from each participant was treated with strict confidentiality.

\section{Data collection}

The data was collected by the researcher and a trained research assistant using semi-structured questionnaires and the Hospital Anxiety and Depression Scale. This scale was used because the study was part of a larger study that assessed both depression and anxiety amongst a cohort of Nigerian outpatients. For respondents who could not understand English, the questionnaire was translated to their native languages. The collected data were sorted, coded and analyzed using the Version 21 of the Statistical Package for Social Sciences (SPSS-21). The level of significance was set at $5 \%(\mathrm{p}<0.05)$.

\section{Results}

\section{Socio-demographic characteristics of participants}

Table 1: Socio-demographic distribution of the respondents $(\mathrm{N}=425)$.

\begin{tabular}{|c|c|c|c|}
\hline \multirow{4}{*}{ Variable } & Category & Frequency & $\begin{array}{c}\text { Percent- } \\
\text { age }\end{array}$ \\
\hline \multirow{4}{*}{ Age (years) } & $20-29$ & 32 & 7.5 \\
\cline { 2 - 4 } & $30-39$ & 66 & 15.5 \\
\cline { 2 - 4 } & $40-49$ & 124 & 29.2 \\
\cline { 2 - 4 } & $50-59$ & 119 & 28 \\
\hline \multirow{4}{*}{ Sex } & $\geq 60$ & 84 & 19.8 \\
\cline { 2 - 4 } & Male & 129 & 30.4 \\
\hline \multirow{4}{*}{ Religion } & Female & 142 & 33.4 \\
\cline { 2 - 4 } & Christianity & 283 & 66.6 \\
\hline \multirow{4}{*}{ Marital Status } & Islam & 320 & 75.3 \\
\cline { 2 - 4 } & Separated or Divorced & 12 & 2.8 \\
\cline { 2 - 4 } & Widowed & 66 & 15.5 \\
\cline { 2 - 4 } & Never Married & 27 & 6.4 \\
\hline
\end{tabular}


The above table 1 showed that $69.6 \%$ and $30.4 \%$ of the study population were females and males respectively. The female: male ratio was $2.3: 1$ and the mean age of the study population was $48.2 \pm 12.93$ years. Respondents within the age group of 40-49years had the highest frequency when the age distribution was considered (29.2\%, $\mathrm{N}=124)$. Muslims were more than the Christian respondents (66.6\% versus $30.4 \%$ ) while the married subjects were more than respondents that belonged to the other marital status (75.3\%). Table 2 above showed that $63.4 \%$ of the married respondents belonged to a monogamous family setting while $92.5 \%$ were Yorubas by tribe. Furthermore, $20.7 \%$ of the respondents had formal education while 164 (38.6\%) and 192 (45.2\%) were self employed or employed as civil servants respectively. Most of the respondents (39.8\%) earned between N 10,000 to N 20,000 monthly while $39.3 \%$ lived in their own apartments. Table 3 above showed the distribution of the respondents based on the HADS scores. Most of the respondents (75.1\%) screened negative for depression while only $1(0.2 \%)$ participant had a severely positive score on the depression subset. Figure 1 above, showed that the prevalence of depression amongst the study population was $24.9 \%$.

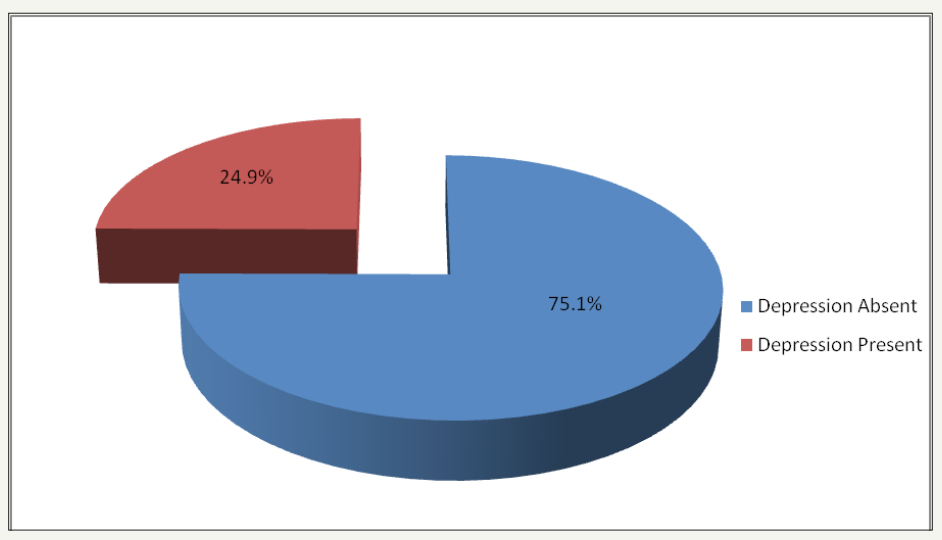

Figure 1: Prevalence of depression.

Table 2: Socio-Demographic Distribution of the Participants $2(\mathrm{~N}=425)$.

\begin{tabular}{|c|c|c|c|}
\hline Variable & Category & Frequency & Percentage \\
\hline \multirow{2}{*}{ Type of Marriage† } & Monogamous & 203 & 63.4 \\
\hline & Polygamous & 117 & 36.6 \\
\hline \multirow{5}{*}{ Ethnicity } & Yoruba & 393 & 92.5 \\
\hline & Hausa & 11 & 2.6 \\
\hline & Igbo & 16 & 3.7 \\
\hline & Fulani & 3 & 0.7 \\
\hline & Others* & 2 & 0.5 \\
\hline \multirow{4}{*}{ Level of Education } & Tertiary & 127 & 29.9 \\
\hline & Secondary & 127 & 29.9 \\
\hline & Primary & 83 & 19.5 \\
\hline & No formal Education & 88 & 20.7 \\
\hline \multirow{4}{*}{ Occupation } & Unemployed & 51 & 12 \\
\hline & Self Employed\# & 164 & 38.6 \\
\hline & Civil Servant & 192 & 45.2 \\
\hline & Schooling & 18 & 4.2 \\
\hline \multirow{5}{*}{ Average Income per Month } & $<\mathrm{N} 5,000$ & 35 & 8.2 \\
\hline & N5,000-N10,000 & 72 & 16.9 \\
\hline & $\mathrm{N} 10,000-\mathrm{N} 20,000$ & 169 & 39.8 \\
\hline & $\mathrm{N} 20,000-\mathrm{N} 40,000$ & 62 & 14.6 \\
\hline & $>\mathrm{N} 40,000$ & 87 & 20.5 \\
\hline
\end{tabular}




\begin{tabular}{|c|c|c|c|}
\hline \multirow{4}{*}{ Tenure of House } & Owned & 167 & 39.3 \\
\cline { 2 - 4 } & Family House & 109 & 25.6 \\
\cline { 2 - 4 } & Rented & 144 & 33.9 \\
\cline { 2 - 4 } & Free to use & 5 & 1.2 \\
\hline
\end{tabular}

$\mathrm{N}=$ Total number of participants, *connotes Ebira, Nupe, etc. \#include Artisans, Farmers, Traders, Private sector workers. †only married participants $(n=320)$.

Table 3: Depression Scores of the Respondents.

\begin{tabular}{|c|c|c|c|}
\hline & Category & Frequency & Percentage \\
\hline \multirow{3}{*}{ Depression Score } & $0-7$ (Negative) & 319 & 75.1 \\
\cline { 2 - 4 } & $8-10$ (Mildly Positive) & 90 & 21.2 \\
\cline { 2 - 4 } & $11-14$ (Moderately Positive) & 15 & 3.5 \\
\cline { 2 - 4 } & $15-21$ (Severely Positive) & 1 & 0.2 \\
\hline
\end{tabular}

\section{Socio-demographic factors and depression}

Table 4 above, showed that depression was noted to have a positive relationship with age (years) and that the prevalence of depression increased as age increased. This relationship between age and depression was found to be statistically significant $(\mathrm{p}=0.045)$. Depression was also noted to be commoner in males $(25.6 \%)$ than in females (24.7\%) though, the relationship between gender and depression was not statistically significant $(\mathrm{p}=0.840)$. Further observation revealed that depression was more in

Table 4: Relationship between socio-demographic characteristics and depression.

\begin{tabular}{|c|c|c|c|c|}
\hline Variable & Depression Absent [ $\left.n_{1}(\%)\right]$ & Present $\left[n_{2}(\%)\right]$ & $\chi^{2}$ & $P$ \\
\hline \multicolumn{5}{|c|}{ Age group } \\
\hline 20-29years & $28(87.5)$ & $4(12.5)$ & & \\
\hline 30-39years & $53(80.3)$ & 13(19.7) & & \\
\hline 40-49years & $97(78.2)$ & $27(21.8)$ & & \\
\hline 50-59 years & $87(73.1)$ & $32(26.9)$ & 9.729 & 0.045 \\
\hline$\geq 60$ years & $54(64.3)$ & $30(35.7)$ & & \\
\hline \multicolumn{5}{|c|}{ Sex } \\
\hline Male & $96(74.4)$ & $33(25.6)$ & & \\
\hline Female & $223(75.3)$ & $73(24.7)$ & 0.041 & 0.84 \\
\hline \multicolumn{5}{|l|}{ Religion } \\
\hline Christianity & 108(76.1) & $34(23.9)$ & & \\
\hline Islam & $211(74.6)$ & $72(25.4)$ & 0.113 & 0.736 \\
\hline \multicolumn{5}{|c|}{ Marital Status } \\
\hline Currently Married & $240(75.0)$ & $80(25.0)$ & & \\
\hline Not Currently Married & $79(75.2)$ & $26(24.8)$ & 0.002 & 0.961 \\
\hline \multicolumn{5}{|c|}{ Type of marriage } \\
\hline Monogamy & $156(76.8)$ & $47(23.2)$ & & \\
\hline Polygamy & $84(71.8)$ & $33(28.2)$ & 1.01 & 0.315 \\
\hline & Ethnic group & & & \\
\hline
\end{tabular}

Muslims (25.4\%) than Christian faithful (23.9\%) and amongst the respondents who were currently married (25.0\%) than those that were not married. Depression was also noted to be more in respondents who were from polygamous families than those from monogamous families. Respondents with no formal education (29.5\%), the unemployed (26.1\%), those who owned their accommodation $(27.1 \%)$ and those who were earning below the minimum wage $(25.4 \%)$ recorded high prevalence rates. However, the relationship between the above variables and the rate of depression was not statistically significant ( $p=>0.05)$. 


\begin{tabular}{|c|c|c|c|c|}
\hline Yoruba & $291(74.0)$ & $102(26.0)$ & & \\
\hline Hausa & $10(90.9)$ & $1(9.1)$ & & \\
\hline Igbo & $14(87.5)$ & $2(12.5)$ & $1.726 \mathrm{Y}$ & 0.631 \\
\hline Others* & $4(80.0)$ & $1(20.0)$ & & \\
\hline \multicolumn{5}{|c|}{ Educational status } \\
\hline Formal Education & $257(76.3)$ & $80(23.7)$ & & \\
\hline No Formal Education & $62(70.5)$ & $26(29.5)$ & 1.257 & 0.262 \\
\hline \multicolumn{5}{|c|}{ Nature of accommodation } \\
\hline Family House & $79(72.5)$ & $30(27.5)$ & & \\
\hline Not Family House & $240(75.9)$ & $76(24.1)$ & 0.522 & 0.47 \\
\hline \multicolumn{5}{|c|}{ Employment status } \\
\hline Employed & $268(75.3)$ & $88(24.7)$ & & \\
\hline Unemployed & $51(73.9)$ & $18(26.1)$ & 0.058 & 0.81 \\
\hline \multicolumn{5}{|c|}{ Average monthly income } \\
\hline Below minimum wage $(<\mathrm{N} 18,000)$ & $206(74.6)$ & $70(25.4)$ & & \\
\hline Minimum wage $\&$ above $(\geq \mathrm{N} 18,000)$ & $113(75.8)$ & $36(24.2)$ & 0.075 & 0.785 \\
\hline
\end{tabular}

$\mathrm{n} 1=$ Number of participants in each category in whom depression was absent

$\mathrm{n} 2=$ Number of participants in each category in whom depression was present

$\%=$ Percentage across each category of the variables.

*Include Fulanis, Ebira, Nupe.

Yconnotes Yates' corrected chi-square.

\section{Discussion}

A prevalence of $24.9 \%$ was reported in this study. This implies that within the study locality, one out of every four respondents was depressed as at the time the study was conducted. The outcome of this descriptive study was comparable to the findings recorded at Uyo and Sagamu where prevalence values of $24.5 \%$ and $29.1 \%$ were obtained respectively $[12,13]$. It is also similar to the findings of $26.3 \%$ reported in Southern Asia [8]. However, the value is lower than the results of studies done in some primary care settings in Ilorin (44.5\%), Ilesa (59.6\%) and Paris, France (56.7\%) [11,14,17]. The disparity could be attributed to the differences in the time/ period of the studies, study designs, sample populations, study areas and research tools used in the various studies.

Out of the $106(24.9 \%)$ respondents that were depressed, majority $(84.9 \%)$ had mild depression, $14.2 \%$ had moderate depression while only one person $(0.94 \%)$ had severe depression. If the prevalence values of mild and moderate depression are summed up, it indicates that majority of respondents could be assisted at the primary care level if the diagnosis was appropriately and timeously made. Family Physicians should be equipped with the skills that would help in the early detection, appropriate diagnosis and treatment of depression. More so, as frontline doctors, they must be equipped with a high index of suspicion in order not to miss the diagnosis of this highly prevalent and yet easily misdiagnosed mental health condition. Family physicians as primary care providers must be aware of the high prevalence of this mental health illness and be ready to screen patients when necessary as undetected and poorly managed cases could lead to suicidal ideations.

The influence of some socio-demographic variables on depression was also considered. Evidence from the index study showed that the only socio-demographic factor that was found to have a statistically significant relationship with depression was age (years). The above observation was in tandem with the finding by Afolabi and colleagues in Ilesa, South west Nigeria where it was also reported that socio-demographic factors such as gender, employment status and religion did not have any statistically significant relationship with the prevalence of depression [14]. Depression was equally found to have a positive relationship with age $(p=0.045)$ and the proportion of the respondents who were depressed across the various age categories increased step-wisely as the age increased in a statistically significant manner. However, the analyses done along all the age categories showed that the prevalence of depression was highest in the age group of 50-59 years. More respondents being represented in this age group could be a possible explanation for the observed disparity.

Similar cross-sectional studies done in Paris, France as well as some parts of Nigeria (Ilesa and Ilorin) recorded the same result $[11,14,17]$. Nevertheless, a contrary finding was reported by Akhtar-Danesh et al. [19] in Canada, where it was observed that the prevalence of depression was highest in the age group 20-24 years. The reason for the disparity might also be related to the differences 
in the study population, tools used in data collection and the study methodologies. Differences in socio-economic factors of the target populations and the influence of some proven socio-demographic variables on depression could have also contributed. The pattern of relationship between age (years) and depression noted in this current study could also be due to the fact that late-life events such as chronic and debilitating medical conditions, loss of spouses and other loved ones and the inability to take part in cherished activities usually take a heavy toll on an aging person's emotional well-being. Also, older adults might sense a loss of control over their quality of live as a result of physical changes associated with ageing and limited financial resources. In addition, older individuals sometimes are preoccupied by thoughts of how well they lived their lives while younger. Some may even have regrets over failure to actualize some of their life dreams when they had the energy and resources while others might be unhappy about the economic situations being faced by their children and grandchildren especially in the presence of economic challenges bedeviling the nation as at the time the study was conducted. The above factors and other related issues could lead to depression.

It was further noted from this study that gender was not significantly associated with depression This trend was similar to the findings in studies done in Ilesa and Sagamu, Nigeria where no association was found between gender and depression $[13,14]$. However, the above observation was contrary to the outcome of a similar study carried out in Ilorin by Shittu et al. [17] and in many other studies done across the world (France, Mexico and Canada) where the prevalence of depression was reported to be higher amongst the female gender [11,17-19]. Perhaps, the different study designs, sample sizes, study populations and research instruments used in the above cited studies might have contributed to the disparities in the findings. The finding of this current study suggests that depression is not gender biased and that males could also be victims of the condition in almost equal frequency. Whether or not this observation was due to the prevailing economic situation of the country as at the time the study was done remains debatable. It is also worthy of note that though the males tend to appear physically stronger, they are not immune to chronic medical and debilitating illnesses as well as other external factors that could predispose to depression. Further studies might be needed to clarify this assertion.

The type of religion the respondents practiced had no significant relationship with depression in this study. This was not surprising as studies in Ilesa, Sagamu and a previous study done in Ilorin also reported a similar finding $[13,14,17]$. This could imply that religion had no role in the occurrence and experience of depressive symptoms in the study population. The two main religions (Islam and Christianity) have also been shown to be similar in many ways [22]. Belonging to an organized religious sect could be a protective factor against depression as social support might be derived from members of such religious sect. Similar to the outcome of the studies done at Ilesa, Nigeria, Zagreb, Croatia and Ontario, Canada $[14,19,20]$, neither being married nor the type of marriage had any significant relationship with depression. This observation was comparable to the finding by Ogunsemi et al. [13] in Sagamu, Nigeria where depression had no significant relationship with marital status. It was however contrary to the finding by Shittu et al. [17] in Ilorin, who reported a significant positive relationship between depression and being married. In these studies, depression was significantly higher among the single, separated, divorced and widowed than the married population. Some studies in Asia have also found polygamy to be associated with depression and other psychopathologies [23-25]. Socio-cultural differences, variations in sample size, study population and methodology could have been responsible for this disparity. The finding in this index study however suggests that being married or the type of marriage did not confer protection against depression. This further corroborates the thought that marriage in itself is not a protective factor against depression but rather the quality of emotional and social support that married partners derive from each other confers protection.

The study reported no statistically significant relationship between educational status and depression. Nevertheless, depression was higher among those with no formal education when compared to those with formal education. This observation was comparable to the findings by Rondet et al. [11] in France where no significant difference was found between the rate of depression and the educational attainment of the studied population but contrary to the observations noted from other similar studies done in Nigeria where the prevalence of depression was significantly higher among those who had no formal education or those with lower level of educational attainment than in those with some formal education or higher level of education $[11,13,14,17]$. The finding of this present study suggests that though formal education might confer some protection against depression by providing better coping mechanisms and problem solving skills, this might not be a significant factor in this center and perhaps in this part of the country. More so, other predisposing factors could have blunted the positive effect of educational status on depression. Nevertheless, further studies are required to fill this knowledge gap.

Employment status and income level did not show any statistically significant relationship with depression in this study. This was similar to the findings by Coker AO et al. [21]; Afolabi et al. [14] in some Nigerian studies, where depression had no significant association with neither employment status nor income level $[14,21]$. Contrary to this observation, was the findings by Shittu et al. [17] in Ilorin, Nigeria and Akhtar-Danesh et al. [19] in Ontario, Canada where employment status and income level were found to have a statistically significant relationship with depression. Depression in the Ilorin and Canadian studies was higher among the employed and in the lower income group. The finding of this current study further suggests that neither being employed nor earning above minimum wage especially in these prevailing times of economic recession was protective against depression. This is not surprising as depression has been known to have many predisposing factors and have been noted to affect people of all socio-economic status. 


\section{Conclusion}

The prevalence of depression as reported in a primary care setting in Nigeria is very high. The study further noted a statistically significant relationship between depression and age. However, no statistical relationship was observed between depression and other socio-demographic and socio-economic factors.

\section{References}

1. https://www.nice.org.uk/guidance/CG91

2. http://www.who.int/mental_health/management/depression/who_ paper_depression_wfmh_2012.pdf

3. World Health Organization (1992) The ICD-10 classification of mental and behavioural disorders. Int Classif 10:1-267.

4. American Psychiatric Association (2013) Diagnostic and statistical manual of mental disorders, $\left(5^{\text {th }}\right.$ edn), (DSM-5). Diagnostic Stat Man Ment Disord, p. 280.

5. Gruenberg AM, Goldstein RD, Pincus HA (2005) Classification of depression : research and diagnostic criteria. DSM-IV and ICD 10. In: Licinio J, Wong M (Eds.), Biology of Depression. From Novel Insights to Therapeutic Strategies. Wiley-Vch Verlag Gmbh \& Co, Weinheim, Germany, pp. 43-54.

6. http://www.who.int/mental_health/management/depression/wfmh_ paper_depression_wmhd_2012.pdf

7. Ferrari AJ, Charlson FJ, Norman RE, Patten SB, Freedman G, et al. (2013) Burden of depressive disorders by country, sex, age, and year: findings from the global burden of disease study 2010. PLoS Med 10(11): 1-12.

8. Reddy MS (2010) Depression: the disorder and the burden. Indian J Psychol Med 32(1): 1-2.

9. Moussavi S, Chatterji S, Verdes E, Tandon A, Patel V, et al. (2007) Depression, chronic diseases, and decrements in health: results from the World Health Surveys. Lancet 370(9590): 851-858.

10. Aillon JL, Ndetei DM, Khasakhala L, Ngari WN, Achola HO, et al. (2014) Prevalence, types and comorbidity of mental disorders in a kenyan primary health centre. Soc Psychiatry Psychiatr Epidemiol 49(8): 12571268.

11. Rondet C, Cornet P, Kaoutar B, Lebas J, Chauvin P (2013) Depression prevalence and primary care among vulnerable patients at a free outpatient clinic in Paris, France, in 2010: results of a cross-sectional survey. BMC Fam Pract 14(1): 151-159

12. Umoh KA, Idung AU (2014) Co-existing mental and medical conditions among family medicine outpatients in a tertiary hospital in Southern Nigeria. Ibom Medical Journal 7(1):1-7

13. Ogunsemi OO, Oluwole FA, Abasiubong F, Erinfolami AR, Amoran OE, et al. (2010) Detection of mental disorders with the patient health questionnaire in primary care settings in Nigeria. Ment Illn 2: 46-50.

14. Afolabi MO, Abioye-Kuteyi EA, Fatoye FO, Bello IS, Adewuya AO (2008) Pattern of depression among patients in a Nigerian family practice population. SA Fam Pract 50(2): 63-63.

15. Obi IE, Aniebue PN, Okonkwo KOB, Okeke TA, Ugwunna N (2015) Prevalence of depression among health workers in Enugu, South East Nigeria. Niger J Clin Pract 18(3): 342-347.

16. Salihu AS, Udofia O (2016) Prevalence and associated factors of depression among general outpatients in a tertiary institution in kano. Open J Psychiatry 6(3): 228-236.

17. Shittu RO, Odeigah LO, Issa BA, Olanrewaju GT (2014) Association between depression and social demographic factors in a Nigerian family practice setting. Open Journal of depression 3(1): 18-23.

18. Bautista CF, Velázquez JV, Icaza MEMM, López MM, Gutiérrez López Mde L, et al. (2012) Socio-demographic and personal factors related to depressive symptomatology in the mexican population aged 12 to 65 . Rev Bras Psiquiatr 34(4): 395-404.

19. Akhtar-Danesh N, Landeen J (2007) Relation between depression and socio-demographic factors. Int J Ment Health Syst 1(1): 4.

20. Milanović SM, Erjavec K, Poljičanin T, Vrabec B, Brečić P (2015) Prevalence of depression symptoms and associated socio-demographic factors in primary health care patients. Psychiatr Danub 27(1): 31-37.

21. Coker AO, Okonkwo L, Kuyinu Y, Adedokun A, Muhammed AS (2014) Screening for psychiatric morbidity in a general outpatient clinic in lagos, Nigeria: the need for a psychiatric presence. J Behav Heal 3(4):225-229.

22. Koenig HG, Zaben FA, Khalifa DA (2012) Religion, spirituality and mental health in the west and the middle east. Asian J Psychiatr 5(2): 180-182.

23. Al-Krenawi A (2013) Mental health and polygamy: the Syrian case. World J Psychiatry 3(1): 1-7.

24. Al-Krenawi A, Graham JR, Al Gharaibeh F (2011) A comparison study of psychological, family function marital and life satisfactions of polygamous and monogamous women in Jordan. Community Ment Health J 47(5): 594-602.

25. Al-Krenawi A (2012) A study of psychological symptoms, family function, marital and life satisfactions of polygamous and monogamous women: The Palestinian case. Int J Soc Psychiatry 58(1): 79-86.
Creative Commons Attribution 4.0 International License

For possible submissions Click Here

\section{Submit Article}

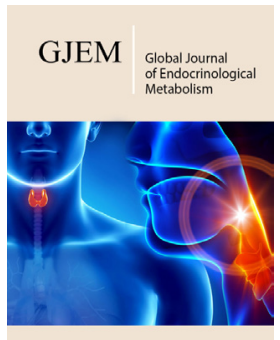

Global Journal of Endocrinological Metabolism

\section{Benefits of Publishing with us}

- High-level peer review and editorial services

- Freely accessible online immediately upon publication

- Authors retain the copyright to their work

- Licensing it under a Creative Commons license

- Visibility through different online platforms 